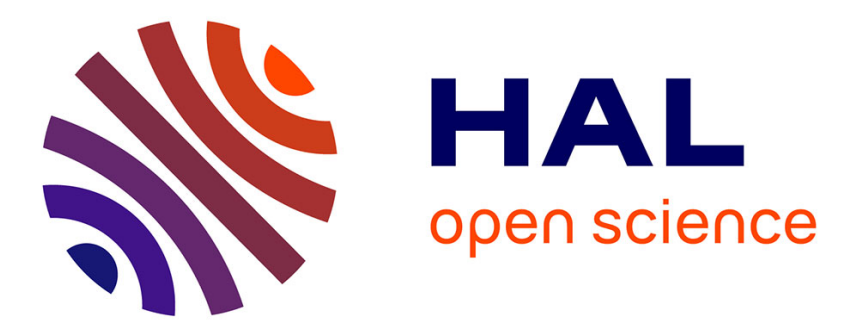

\title{
Modeling of a Polishing Tool to Simulate Material Removal
}

Anthony Guiot, Stéphane Pattofatto, Christophe Tournier, Luc Mathieu

\section{To cite this version:}

Anthony Guiot, Stéphane Pattofatto, Christophe Tournier, Luc Mathieu. Modeling of a Polishing Tool to Simulate Material Removal. 13th CIRP Conference on Modelling of Machining Operations, May 2011, Sintra, Portugal. pp.754-763, 10.4028/www.scientific.net/AMR.223.754 . hal-01223976

\section{HAL Id: hal-01223976 https://hal.science/hal-01223976}

Submitted on 3 Nov 2015

HAL is a multi-disciplinary open access archive for the deposit and dissemination of scientific research documents, whether they are published or not. The documents may come from teaching and research institutions in France or abroad, or from public or private research centers.
L'archive ouverte pluridisciplinaire HAL, est destinée au dépôt et à la diffusion de documents scientifiques de niveau recherche, publiés ou non, émanant des établissements d'enseignement et de recherche français ou étrangers, des laboratoires publics ou privés. 


\title{
Modeling of a polishing tool to simulate material removal
}

\author{
A. Guiot ${ }^{1^{*}}$, S. Pattofatto ${ }^{2}$, C. Tournier ${ }^{1}$, L. Mathieu ${ }^{1}$ \\ ${ }^{1}$ LURPA, ENS Cachan / Université Paris Sud 11, 61 av du Pdt Wilson 94230 Cachan (France) \\ ${ }^{2}$ LMT Cachan, ENS Cachan / Université Paris 6, 61 av du Pdt Wilson 94230 Cachan (France) \\ *anthony.guiot@lurpa.ens-cachan.fr
}

\begin{abstract}
In plastic injection mould and prosthesis industries, "mirror-effect" polished surfaces are required for obtaining transparent parts or surfaces without scratches. Traditionally done manually, we have proposed to automate polishing on 5-axis machining centre using a passive elastomeric carrier. One of the main advantages of automatic polishing is the repeatability of the machine movements in order to achieve restricted form deviations. However, the material removal rate (MRR) during polishing depends on parameters such as contact pressure, relative velocity and tool wear. We have thus developed a model dedicated to our process to compute the effective MRR along the polishing tool path regarding the contact area and the contact pressure between the tool and the part.
\end{abstract}

\section{INTRODUCTION}

The development of High Speed Machining (HSM) has dramatically modified the organization of plastic injection molds and tooling manufacturers. HSM in particular reduces mold manufacturing cycle times by replacing spark machining but does not enable to remove the polishing operations from the process.

As the usual polishing process is expensive in terms of price and downtime of the mold, we have developed an automatic polishing process on 5-axis machine tool [1]. Our approach consists in using the same tools as those used in manual polishing for pre-polishing and finishing polishing (Figure 1). Pre-polishing is performed with abrasive discs mounted on a carrier. This carrier is a deformable part made in an elastomer material fixed on a steel shaft that allows mounting in the spindle. Hence, we do not have a force feedback control but we manage the polishing force with the length of the tool introduced in the numerical controller. The polishing strategies are for the most part issued from previous experiences as for trochoidal tool paths (figure 1) computed on fractal trajectories coming from robotized polishing or cycloidal weaving paths representative of manual polishing [2],[3],[4].

The main advantage of this process is the repeatability of the machine movements to respect the specified form deviation. Indeed, in manual polishing the material removal rate (MRR) depends on the polishing tool velocity and on the polishing pressure applied by the operator. An adequate polishing force facilitates the removal of cusps and stripes left on the part during milling or previous polishing operations. Nevertheless, the contact pressure has to be as constant as possible to avoid over-polishing and respect form deviation tolerances. Furthermore, even if the effective MRR is quit constant, the polishing time spent in every area of the part and consequently the polishing velocity along the tool path has to be constant and the distribution of the tool path has to be consistent.

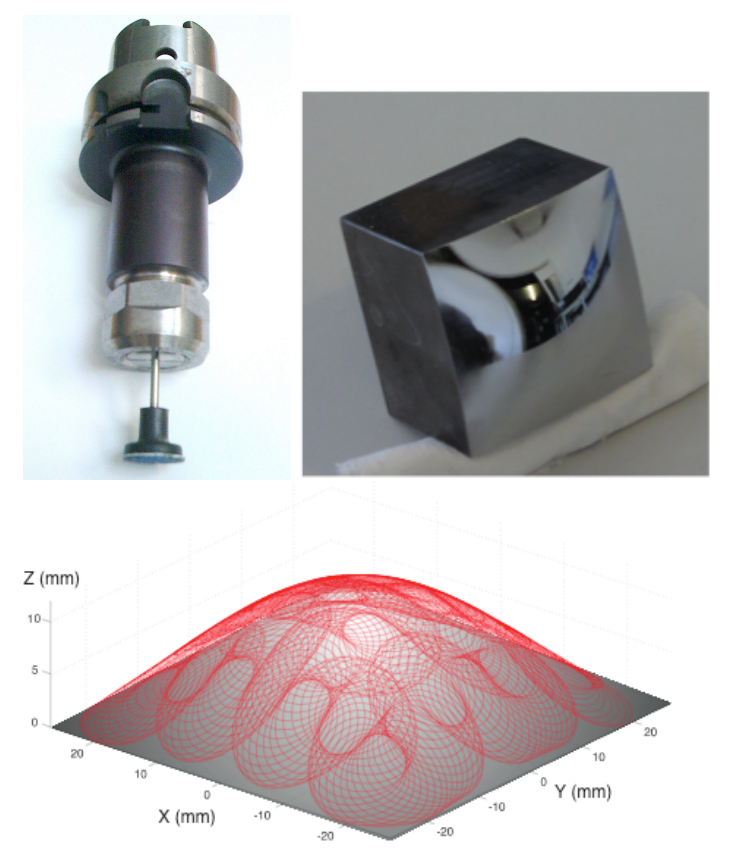

Figure 1: Polishing tool and trochoidal tool paths.

The aim of the paper is thus to propose a tool to simulate the material removal during polishing. The final objective is to provide a tool to optimize polishing parameters along the tool path (spindle speed, feedrate, imposed dis- 
placement) and the tool path itself in order to manage geometrical deviations.

In the next section several models of the material removal rate from the literature are presented. Then in section 3 we will present our simulation tool and the tool wear evaluation. Section 4 is dedicated to the modeling of the behavior of the disc carrier by using Finite Element Analysis. Simulations are analyzed in section 5 through experimental investigations before concluding remarks in section 6 .

\section{RELATED WORKS}

The measurement or quantification of abrasion is most frequently given by the material removal rate (MRR), that is to say, the thickness of material removed per time unit. We can find two different approaches to model the MRR, the analytical models and the experimental models [5].

The analytical models are based on modeling the interaction between the tool and the workpiece at the level of the abrasive particle [6] [7] [8]. We find these approaches in the electronics industry in particular for wafer polishing. The proposed models give an estimate of the material removal rate from all material characteristics (Young's modulus, hardness, Poisson's ratio), shape of the surface (type, size, distribution of asperities and particles) and the operating conditions (pressure, relative velocity, the effect of a chemical or fluid).

There is no comparable model for the realization of mechanical parts. The models used for polishing of these materials are rather experimental models. The experimental models are derived from the analysis of many polishing trials. The model of Preston [9], developed within the context of glass polishing, is probably the one that remains today the most used (eq.1). It states that the material removal rate is proportional to the average pressure of contact, $\mathrm{P}$, and to the tool/part relative velocity $\mathrm{V}$ :

$M R R=\frac{d z}{d t}=k \cdot P \cdot V$

The coefficient of proportionality also called "Preston coefficient" $K$ is determined experimentally and depends on process parameters (part material, abrasive, lubrification, etc.).

In their work, Luo et al. [10] studied the influence of the fluid for copper polishing. In addition to mechanical mechanisms, they highlight the fact that there are chemical mechanisms involved in abrasion. The proposed model is a slight evolution of the Preston model:

$M R R=\left(K_{1} \cdot P+B\right) V+R_{c}$

Where $K_{1}, B$ and $R_{c}$ are three constants to be determined experimentally. $R_{c}$ is the rate of material removal due to the chemical mechanism.

Wang et al. [11] also proposed an extension of the Preston model for the manufacture of storage disk made of aluminum and magnesium alloy or glass-ceramic material:

$M R R=K_{2} \cdot P^{n / 2} \cdot V^{1-n / 2}$

$K_{2}$ and $n$ are two constants to be determined experimentally. This model seems to give good results for different materials.

Finally, analytical models have the advantage of predicting the removal material rate from all process data, which can also be a drawback because the knowing of all the physicochemical properties of the polishing components is mandatory. The experimental models are used for diverse materials. Preston's equation was originally used for polishing glass, but is now used for metal or semiconductor polishing. Whatever the model, the MRR always depends on pressure and relative velocity between the tool and the part.

However, literature models do not take into account the wear of the abrasive tool. Furthermore, these models have been developed for planar polishing on automatic machines. Thus, the contact area between the abrasive disk and the part is always a plane so that the contact pressure is uniform over the part. The relative velocity between the part and the tool is a combination of the tool and part rotation speed. In automatic polishing, the cutting speed $V c$ of the tool is one hundred larger than the tool feedrate $V f$, and $V f$ is not constant when polishing on a 5-axis machine tool [12].

The contact area and the pressure distribution could be determined by finite element computation, taking into account the disk carrier material behavior, inclination and position of the tool. This will be developed in section 4 . In a first approach, we consider that the pressure distribution in the contact area is uniform and the form and size of the contact area are supposed constant. This allows the definition of our simulation tool presented hereafter. 


\section{PROPOSED MODEL FOR MATERIAL REMOVAL RATE SIMULATION}

Our simulation tool is based on the Preston model to compute the cutting depth per time unit. It takes into account effective cutting speed at each point of the contact area as well as the effective feedrate.

A global model is first proposed and in a second step, the tool wear, the geometry of the contact area and the pressure distribution are investigated and included in the model.

\subsection{Global approach}

As mentioned in the previous section, there are many abrasion models, but in mechanical and particularly for the polishing of molds and dies, the easiest model to use is based on the Preston equation (eq.1). Using this equation for a little element of surface that can be assumed to be a plane of normal $z$, it is equivalent to write during a little time $\Delta t$ :

$\Delta z=K . P \cdot V_{c} \cdot \Delta t$

The cutting depth $\Delta z$ is proportional to the polishing time spent on an area of the part, which is in contact with the disk. If the pressure and the velocity are kept constant during polishing, one can think that the MRR will be constant. Actually, the disk efficiency is different over the time because of its wear. Hence, the Preston coefficient $K$ depends on time and it will be decomposed by the product of the initial Preston coefficient $K_{0}=K_{(t=0)}$ and a decreasing time function representative of the efficiency of the abrasive disk (wear law) $w(t)$.

The Preston coefficient $K(t)$ can be expressed as follow:

$K(t)=K_{0} \cdot w(t)$

Hence the Preston equation becomes:

$\Delta z=K_{0} \cdot w(t) \cdot P \cdot V c \cdot \Delta t$

If we consider a constant cutting speed, we can define a nominal material removal rate $M R R_{0}$ :

$M R R_{0}=K_{0} \cdot P \cdot V c=c s t$

$\Delta z=M R R_{0} \cdot w(t) \cdot \Delta t$

In order to go further in the definition of the model, we need to define the contact area. In a first approach, the contact area is modeled by an ellipse with a minor axis $2 a$ and a major axis $2 b$ (figure 2) and the pressure distribution is supposed to be constant.

The first step of the method consists in meshing the surface to polish and sampling the tool path according to a maximum length between points I_max, initially fixed by the user.

The result is a list of $n$ points $M(i)$ such as:

$|\mathrm{M}(\mathrm{i}+1)-\mathrm{M}(\mathrm{i})|<$ I_max

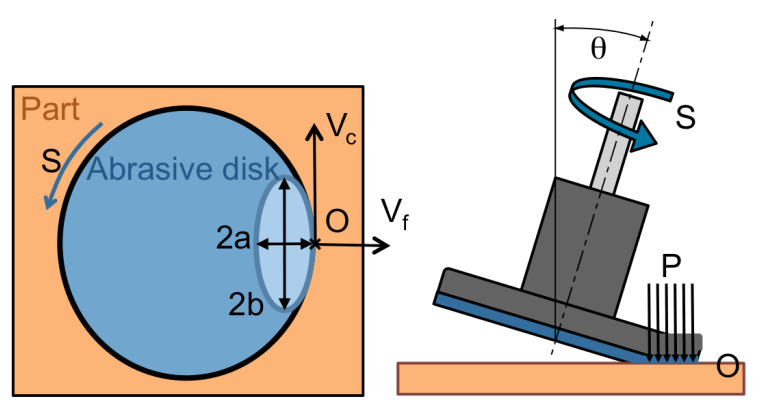

Figure 2: Tool/surface contact.

Then for each point $M(i)$ of the tool path, the contact area is positioned such as the point $O$ (tool location) corresponds to the point $M(i)$ and oriented along the inclination direction $\theta$ (figure 3).

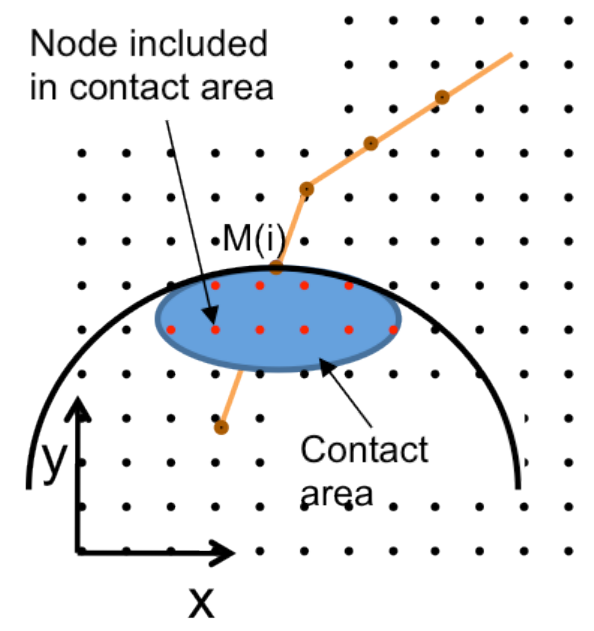

Figure 3: Simulation model.

When the contact area is in place, any node $j$ among the $m$ nodes of the mesh is marked in a $(n, m)$ dimension matrix Ins $(i, j)$. Any point included in the contact area (red points) takes the logical value 1 and all others take the logical value 0 .

Along all segment $i$ included between points $M_{i}$ and $M_{i+1}$, the feedrate $V f$ and wear law $w(t)$ are supposed to be constant. Thus the segment travel time can be approximated by:

$$
\Delta t_{i}=\left|M_{i+1}-M_{i}\right| / V f_{i}
$$

Taking I_max small enough allows making the assumption that the points in contact for the position $M_{i}$ still in contact during the entire segment $i$.

Now it is simple to obtain the abrasion time $T(j)$ for each node of the mesh: 
$T(j)=\sum_{i=1}^{n} \Delta t_{i} \cdot \ln s(i, j)$

We define the local abrasion time for each node $T_{w}(j)$ weighted by the tool wear:

$T_{w}(j)=\sum_{i=1}^{n} w\left(t_{i}\right) \cdot \Delta t_{i} \cdot \ln s(i, j)$

Finally, the cutting depth $D(j)$ at the node $j$ is obtained by the relation:

$D(j)=M R R_{0} \cdot \sum_{i=1}^{n} w\left(t_{i}\right) \cdot \Delta t_{i} \cdot \ln s(i, j)$

We thus have exposed a model to predict the cutting depth based on a theoretical contact area between the tool and the part modeled has an ellipse with constant pressure distribution. The next section focuses on the definition of the tool wear.

\subsection{Tool wear identification}

The tool wear has been identified experimentally by polishing plane stripes and measuring the polishing depth along the stripes. Since the feedrate has been kept constant during the test, the correlation between efficiency and time can be established. The tool wear evolution plotted in Figure 4 corresponds to an abrasive paper of grade 600 , a spindle speed of 2000 $\mathrm{rpm}$, a feedrate of $1 \mathrm{~mm} / \mathrm{s}$ and an impose displacement of $0.5 \mathrm{~mm}$. The material is a mold steel X35CrMoV5 (Hrc 53). The model of the tool wear law associated to the experiment is the following:

$w(t)=0.29+0.71 \cdot e^{-\frac{t}{40}}$

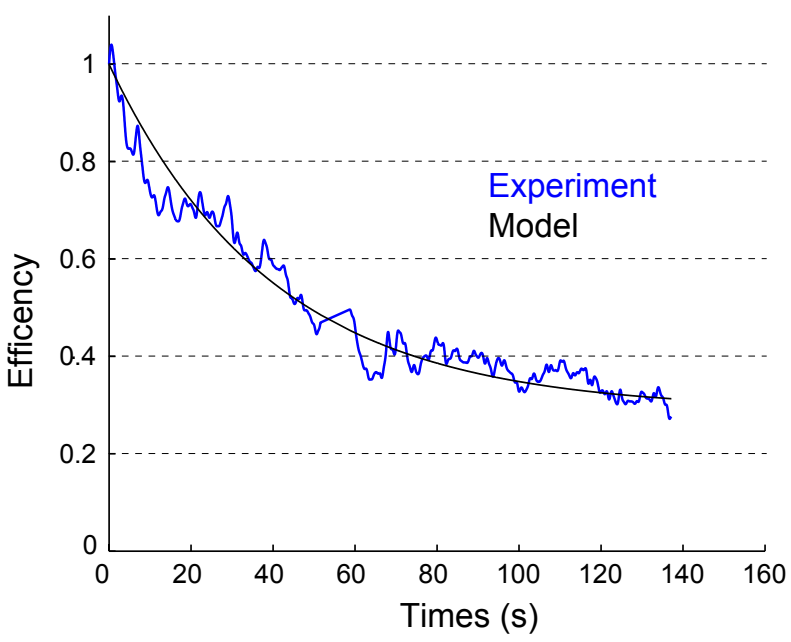

Figure 4: experimental tool wear evolution.
The next section focuses on the definition of the effective contact area by using finite element analysis.

\section{ELASTOMERIC CARRIER MODELING}

The purpose of this section is to model and simulate the mechanical behavior of the disc carrier when pressed on the workpiece. The geometry of the contact area and pressure distribution at the interface with the workpiece are computed regarding the imposed displacement and the angle between the tool axis and workpiece. The steel tool shaft is modeled as a virtual part of infinite rigidity in the simulation. In this section, the abrasive disk is not taken into account. Simulation results are compared to experimental investigations.

\subsection{Numerical simulation set up}

The disc carrier is made of elastomeric material the composition of which is unknown exactly. Traction tests allowed us to determine the value of Young's modulus $\mathrm{E}(9 \mathrm{MPa})$. The Poisson coefficient has been set to 0.49 as much of the elastomeric materials. We consider a purely elastic behavior of the disc carrier. The connection between the disc carrier and the shaft is modeled as a rigid joint and the part is considered as infinitely rigid. The desired displacement is imposed along the shaft axis. The disc carrier has a diameter of $18 \mathrm{~mm}$ and is meshed with tetrahedral elements of maximum size equal to $0.5 \mathrm{~mm}$ (Figure 5 ).

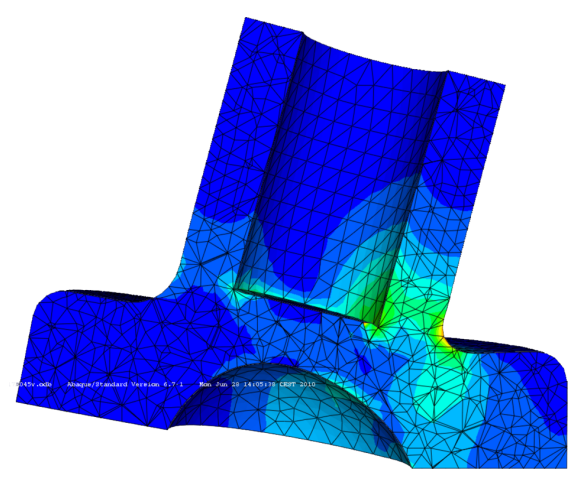

Figure 5: Numerical simulation.

\subsection{Experimental validation}

To validate the numerical simulation, the tool has been photographed during its deformation on a plate of polycarbonate. The following pictures show the comparison for imposed displacements equal to $0.6,1.4$ and $1.8 \mathrm{~mm}$ (Figure 6$)$. We see that there is a very good correlation between testing and simulation. It is interesting to observe how the contact area evolves according to the imposed displace- 
ment. For low compression, the contact zone is located at the front of the disk on a thin strip. When the compression increases, the contact area grows and divides into two peripheral areas.

Finally, for larger compression, contact area as well as the maximum pressure converge to the inside edge of the disc carrier. There is also a loss of contact in the area at the front of the tool that does not appear clearly in the experimental results.

We therefore have a modeling tool of the compression of the disk that gives satisfactory results regarding the geometry of the contact area. However, the distribution of pressure field at the contact has not been confirmed yet.
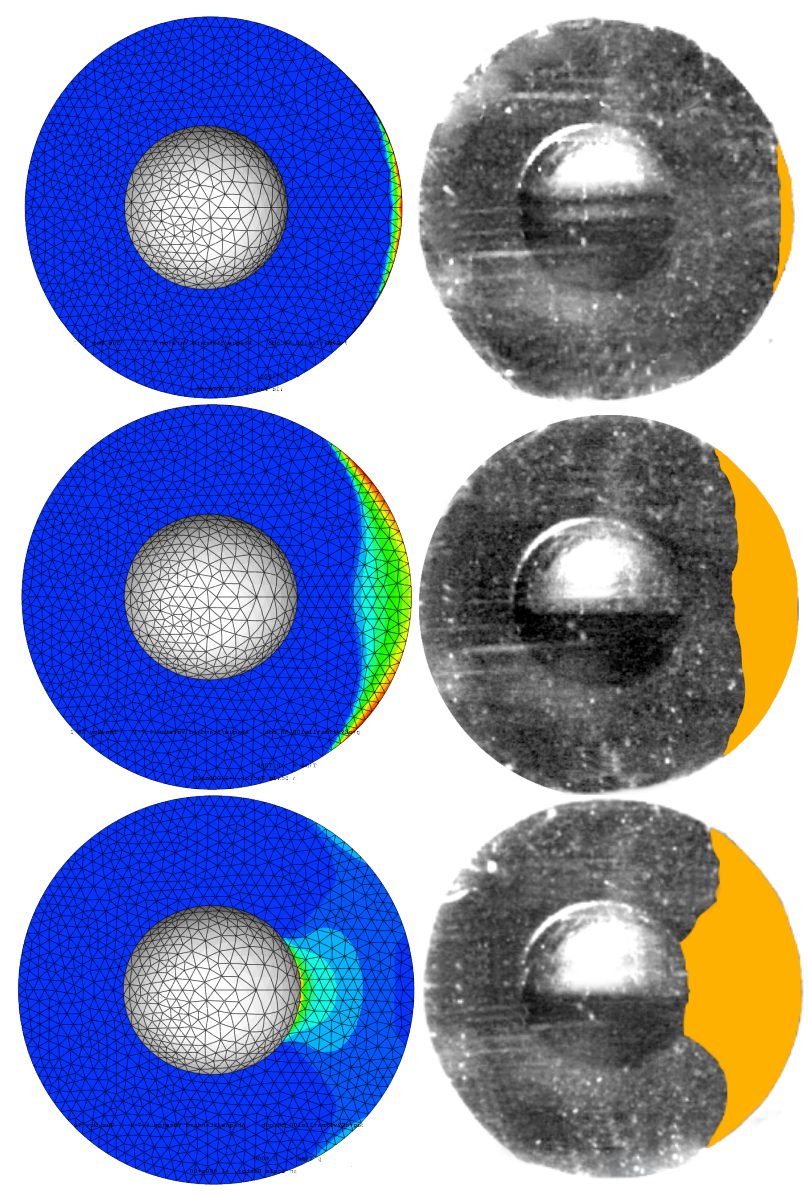

Figure 6: Simulation and experiment (imposed displacements: $0.6 ; 1.4 ; 1.8 \mathrm{~mm}$ ).

\section{EXPERIMENTAL INVESTIGATIONS}

The experiment allows us to show correlations and differences obtained between simulation and geometrical deviation. The test surface is a planar face the section of which is $50 \mathrm{~mm} \times 50$ $\mathrm{mm}$ machined in a stock made of $\mathrm{X} 35 \mathrm{CrMoV} 5$ (Hrc 53) steel.
- The plane is milled using a $12 \mathrm{~mm}$ diameter hemispherical tool along parallel planes so that the scallop height is inferior to $2 \mu \mathrm{m}$.

- Pre-polishing operation is performed with a $18 \mathrm{~mm}$ diameter abrasive disk made of silicon carbide (grade 600). Tool paths are trochoidal trajectories based on parallel planes (Figure 7). The distance between planes is set to $13 \mathrm{~mm}$, the trochoid diameter and step are set to $8 \mathrm{~mm}$ and $0.8 \mathrm{~mm}$ respectively. The imposed displacement is $0.5 \mathrm{~mm}$ leading to a contact force of $5 \mathrm{~N}$ [1]. The programmed feedrate $(2 \mathrm{~m} / \mathrm{min})$ is reach during most of the operation.

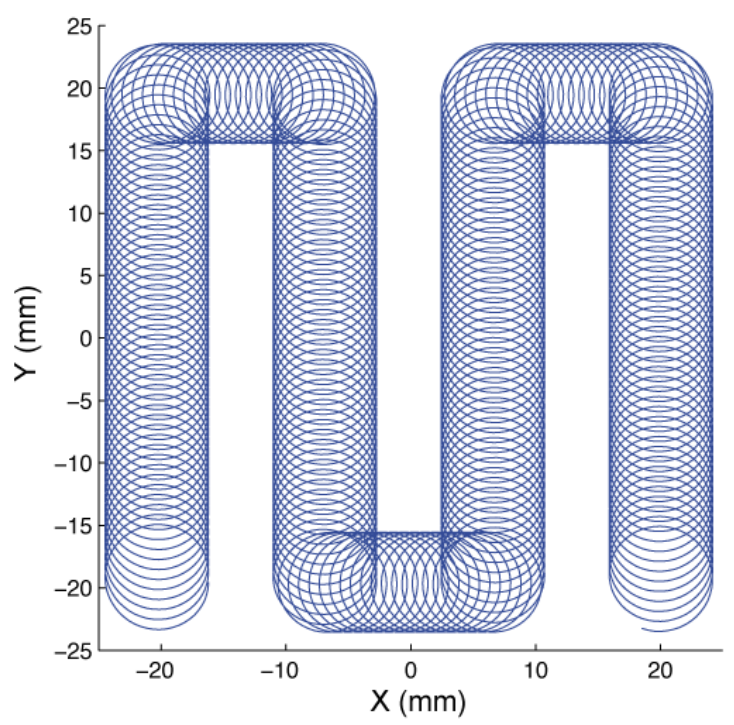

Figure 7: Polishing trajectory.

Measurements are carried out with a noncontact sensor based on chromatic confocal technology (Figure 8). Measurement steps along $X$ and $Y$ axes are set to $50 \mu \mathrm{m}$. Tool bath has been superposed to the $Z(X, Y)$ cartography. It can be observed that the material removal is greater where the tool path overlaps, leading to geometrical deviation values up to $4 \mu \mathrm{m}$. The loss of polishing efficiency along the tool path is also visible.

The following simulation includes the wear law $w(t)$ computed in section 3.2. However the value of $M R R_{0}$ is not known before the simulation. Therefore the relevance of the results lies in the mapping of geometrical deviations rather than their absolute values.

The first simulation is computed by considering an elliptic contact area. The minor axis $2 a$ $(2.4 \mathrm{~mm})$ is determined by measuring the area of the disk soiled by chips and the major axis $2 b(5 \mathrm{~mm})$ is determined by measuring the 


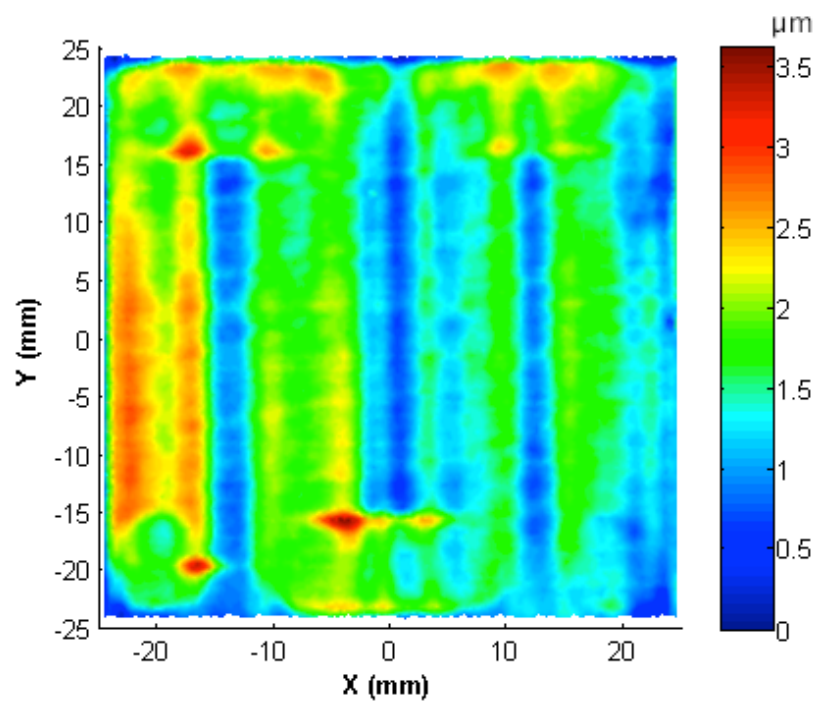

Figure 8: Measurement.

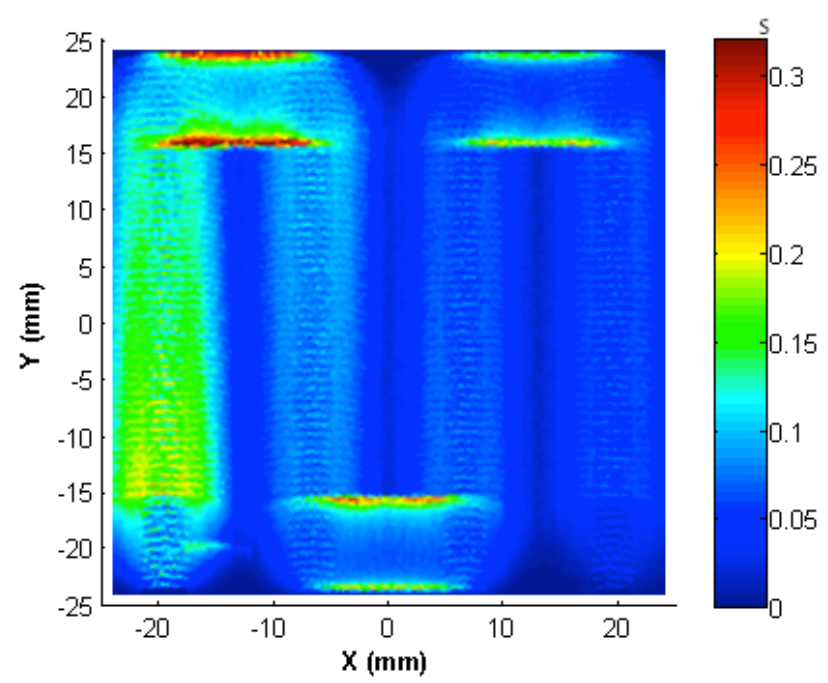

Figure 10: "FEA" simulation.

width of the polished area for a straight-line tool path. A constant and uniform pressure distribution $P$ has been used. Thus, the result of this first simulation depicted on Figure 9 shows the mapping of the local polishing time weighted by the tool wear $T w(j)$ (eq. 12). We are able to distinguish the polished areas and where the tool path overlaps. It seems that the efficiency of the abrasive disk along the tool path is under estimated.

A second simulation has been computed by using the contact area issued from the finite element analysis without the abrasive paper (Figure 10). This simulation represents the mapping of $T w(j)$ (eq. 12). The contact area is included in the term Ins(i,j). There is a significant difference between simulation and measure.

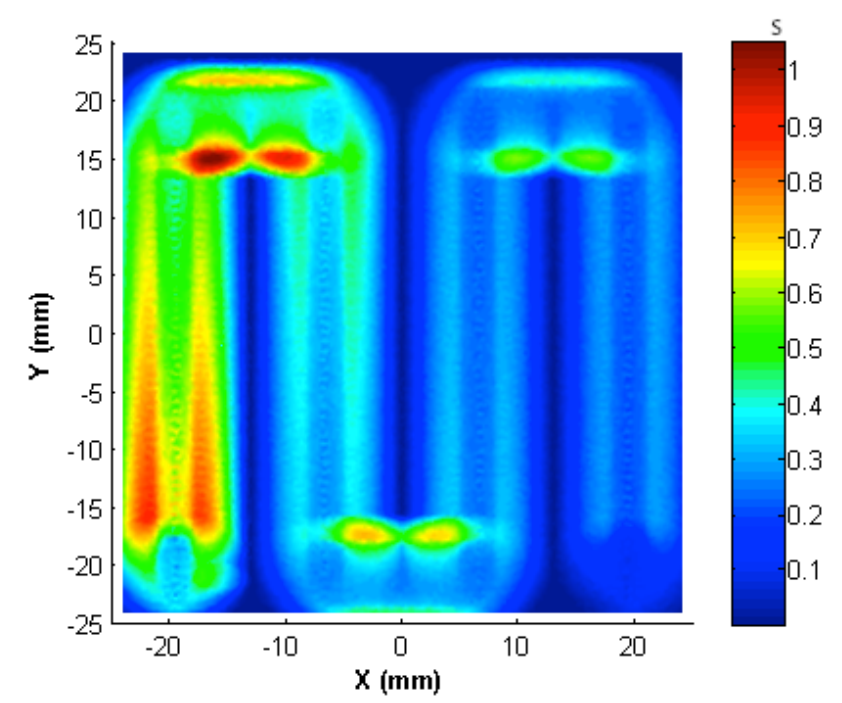

Figure 9: "Elliptic" simulation.

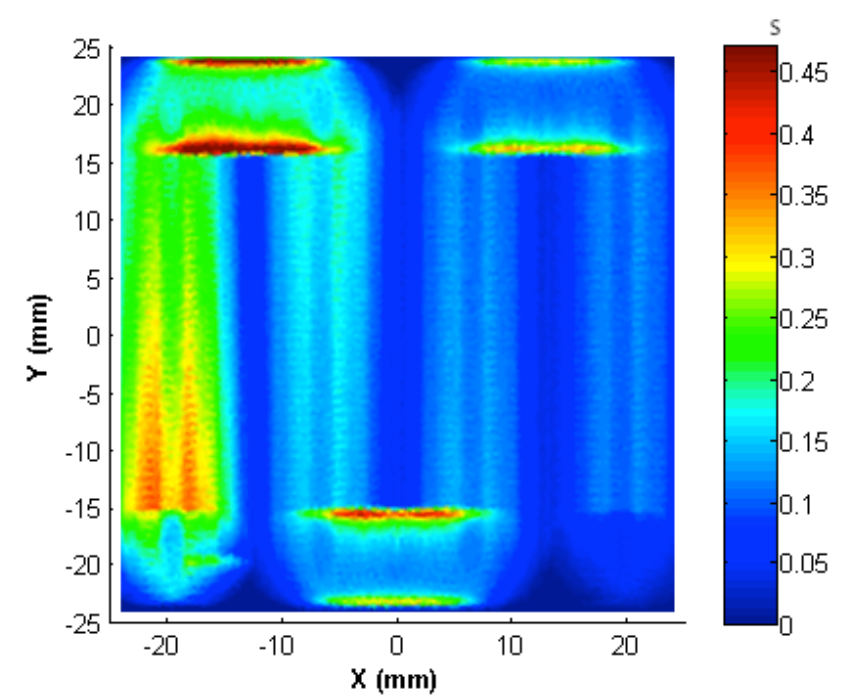

Figure 11: "FEA" with abrasive paper.

The pseudo time (s) spent on each point of the surface is half as large as in the previous simulation. The contact area seems to be thinner than the real one. We are able to distinguish each arc of the trochoid tool path.

A third simulation including the abrasive paper has been conducted (Figure 11). The abrasive paper is introduced as an additional part with a purely elastic behavior in the finite element analysis. An approximate Young modulus has been identified through a compression test of several superposed abrasive disks $(E=22 \mathrm{MPa})$. The thickness of the contact area is greater leading to a superior local polishing time. The abrasion topography is much more satisfying and is closer to the real part and to the elliptic simulation. 


\section{CONCLUSION AND FUTURE WORKS}

In this paper we have presented a simulation tool to predict the geometrical deviation due to polishing operation with abrasive paper. The model is based on Preston equation and includes tool wear and contact area modeling.

The simulation results are quite satisfactory, although they are not perfect. The introduction of FEA including the abrasive paper in the simulation provides good results. Although the simulation of the deformation of the disc carrier is satisfying, the modeling of the contact area must be improved.

The tool wear is established for the same set of tool and workpiece material and for the same polishing parameters. However, the abrasion efficiency seems to be under estimated.

The simulation tool has been tested for planar polishing but we intend to extend our model on convex and concave surfaces. Then we will be able to tunes the polishing strategy (imposed displacement, feedrate and tool path) in order to manage the geometrical deviations on free form surfaces.

\section{ACKNOWLEDGMENTS}

This work is founded by the French Ministry of Research.

It was carried out within the Manufacturing 21 working group, which comprises 16 French research laboratories. The topics covered are: modeling of the manufacturing process, virtual machining and emergence of new manufacturing methods.

\section{REFERENCES}

[1] Pessoles, X., Tournier, C., 2009, Automatic polishing process of plastic injection molds on a 5-axis milling center, Journal of Materials Processing Technology, 209/7:36653673.

[2] Mizugaki, Y., Sakamoto, M., 1992, Fractal path generation for a metal-mold polishing robot system and its evaluation by the operability. Annals of the CIRP, 41/1: 531534.

[3] Tam, H.-Y., Lui, O.H., Mok, A., 1999, Robotic polishing of free-form surfaces using scanning paths. Journal of Materials Processing Technology, 95/1-3: 191-200.

[4] Tsai, M. J., Huang, J. F., 2006, Efficient automatic polishing process with a new compliant abrasive tool. International Journal of Advanced Manufacturing Technology, 30: 817-827.
[5] Nasri, H., Bolmsjö, G., 1994, A process model for robotic disc grinding. International Journal of Machine Tools and Manufacture, 35: 503-510.

[6] Bai, J., Zhao, Y.W., Wang, Y.G., 2007, A mathematical model for material removal and chemical-mechanical synergy in chemical-mechanical polishing at molecular scale. Applied Surface Science, 253: 8489-8494.

[7] Jiang, J-Z., Zhao, Y-W., Wang, Y-G., Luo, J-B., 2008, A chemical mechanical polishing model based on the viscous flow of the amorphous layer. Wear, 265:992-998.

[8] Oh, S., Seok, J., 2009, An integrated material removal model for silicon dioxide layers in chemical mechanical polishing processes. Wear, 266:839-849.

[9] Preston, F.W., 1927, The theory and design of plate glass polishing machines. Journal of the Society of Glass Technology, 11:214-256.

[10] Luo, Q., Ramarajan, S., Babu, S.V., 1998, Modification of the Preston equation for the chemical-mechanical polishing of copper. Thin Solid Films, 335:160-167.

[11] Wang, C-C., Lin, S-C., Hochen, H., 2002, A material removal model for polishing glass-ceramic and aluminium magnesium storage disk. International Journal of Machine Tools and Manufacture, 42:979-984.

[12] Lavernhe, S., Tournier, C., Lartigue, C., 2008, Kinematical performance prediction in multi-axis machining for process planning optimization. International Journal of Advanced Manufacturing Technology, 37/5-6:534-544. 
